\title{
Effects of ultrasound-assisted botulinum neurotoxin-A injection in patients with bruxism and masseter hypertrophy
}

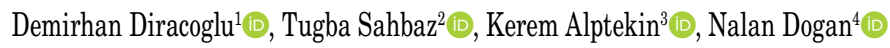 \\ ${ }^{1}$ Department of Physical Medicine and Rehabilitation, Istanbul University, Istanbul Faculty of Medicine, Istanbul, Turkey \\ ${ }^{2}$ Department of Physical Medicine and Rehabilitation, University of Health Sciences, Kanuni Sultan Süleyman Training and Research Hospital, Istanbul, Turkey \\ 3Department of Physical Medicine and Rehabilitation, Bahçeşehir University, Health Sciences Faculty, Istanbul, Turkey \\ 4Department of Physical Medicine and Rehabilitation, Beykoz State Hospital, Istanbul, Turkey
}

Received: March 20,2020 Accepted: October 09, 2020 Published online: September 01, 2021

\begin{abstract}
Objectives: This study aims to explore effects of ultrasound-assisted injection of the botulinum neurotoxin-A (BoNT-A) on muscle thickness (MT) in patients with masseter hypertrophy.

Patients and methods: Between December 2018 and December 2019, a total of 20 patients ( 3 males, 17 females; mean age: $28 \pm 6.9$ years; range, 18 to 42 years) with bruxism who underwent BoNT-A injections were reviewed retrospectively. The patients were treated using individualized injection dosages and sites. Assessment methods included length between the tragus and the angle of the mouth, maximal bite force, and MT of the masseter muscle. Follow-up data were collected from the hospital electronic database.

Results: There were 26 masseter muscles with masseter hypertrophy in 20 patients. There was a significant difference in ultrasonographic measurements of the relaxed and contracted masseter muscles between the baseline and two weeks, one month and three months after the treatment $(\mathrm{p}<0.05)$. In the ultrasonographic measurement of the relaxed masseter muscle, post-treatment third month values significantly differed from the second week values. The differences in the measurement of the line between the tragus and the angle of the mouth between the baseline and two weeks, one month and three months after the treatment were statistically significant ( $<<0.05)$. In the maximal bite force measurements, no significant difference was observed between the baseline and post-intervention measurements ( $>0.05$ ).

Conclusion: The MT decreases after a single dose of BoNT-A injection in patients with masseter muscle hypertrophy and ultrasonography is a convenient imaging modality for BoNT-A injection to the masseter.
\end{abstract}

Keywords: Botulinum toxin-A, bruxism, dystonia; masseter hypertrophy, spasticity, ultrasonography.

Bruxism, clenching or grinding of the teeth, is a common problem in adult population. Although the etiology is still uncertain, anxiety and stress, asymmetry of teeth, digestive and sleep disturbances are related to bruxism. ${ }^{[1]}$ On the other hand, masseter muscle hypertrophy is a cause of bruxism. ${ }^{[2-5]}$ Although previous studies have established the beneficial effects of botulinum neurotoxin-A (BoNT-A) injections in patients with masseter hypertrophy and bruxism, ${ }^{[6-9]}$ there is a limited number of data regarding the ultrasound (US) assistance during the injection of the BoNT-A to the masseter muscles. ${ }^{[10,11]}$ Quezada-Gaon et al. ${ }^{[10]}$ reported anatomical variations of the salivary glands in up to $65 \%$ of their sample size. Erroneous location and incorrect needle size were seen frequently ( $40 \%$ and $20 \%$ of the cases, respectively) with blind injection technique. Maximal bite force (MBF) is a term that refers to the maximum occlusal force a person can create during biting. The effect of the bruxism on bite force is unclear. While some studies have measured

Corresponding author: Tuğba Şahbaz, MD. SBÜ Kanuni Sultan Süleyman Eğitim ve Araştırma Hastanesi Fizik Tedavi ve Rehabilitasyon Kliniği, 34303 Küçükçekmece, İstanbul, Türkiye. e-mail: piskint@gmail.com 
MBF to be increased in bruxism patients, some have measured to be unaltered or even decreased. ${ }^{[12-15]}$

In the present study, we aimed to explore in vivo effects of US-assisted injection of the BoNT-A on muscle thickness (MT) measured by US and MBF change in patients with masseter hypertrophy after treatment.

\section{PATIENTS AND METHODS}

This retrospective study was conducted at Istanbul University, Istanbul Medical Faculty, Department of Physical Medicine and Rehabilitation between December 2018 and December 2019. Medical records of a total of 20 patients ( 3 males, 17 females; mean age: $28 \pm 6.9$ years; range, 18 to 42 years) who had masseter hypertrophy due to bruxism (unilateral or bilateral) and underwent BoNT-A injections were included. Patients with any of temporomandibular joint disorder apart from the bruxism such as disc displacement, degenerative joint disease, jaw trauma or deformity, any history of BoNT-A injection, dental pathology preventing biting, neurological or psychiatric disorders were excluded from the study. A written informed consent was obtained from each patient. The study protocol was approved by the
Istanbul University, Istanbul Medical Faculty Ethics Committee (No: 2019-445). The study was conducted in accordance with the principles of the Declaration of Helsinki.

\section{Data collection and assessments}

Clinical and demographical features of the patients such as age, sex, and body mass index were noted. All patients were examined with respect to the dental or tongue erosions. Measurements of the length of the line drawn between the tragus and the angle of the mouth and MBF measurements were obtained with the use of Istanbul bite force recorder. ${ }^{[12]}$ Baseline measurements and follow-up data of two weeks, one month, and three months post-injection were retrieved from the hospitals electronic database. A control visit was recommended in case of an adverse/unexpected event.

\section{Ultrasound evaluation}

The patients underwent an US evaluation in B-mode using a linear-array transducer $(7-12 \mathrm{MHz})$ prior to the injection to confirm the location and thickness (mm) of the masseter muscles, as well as the presence of anatomical variations. The probe was placed in transverse axis and masseter thickness was
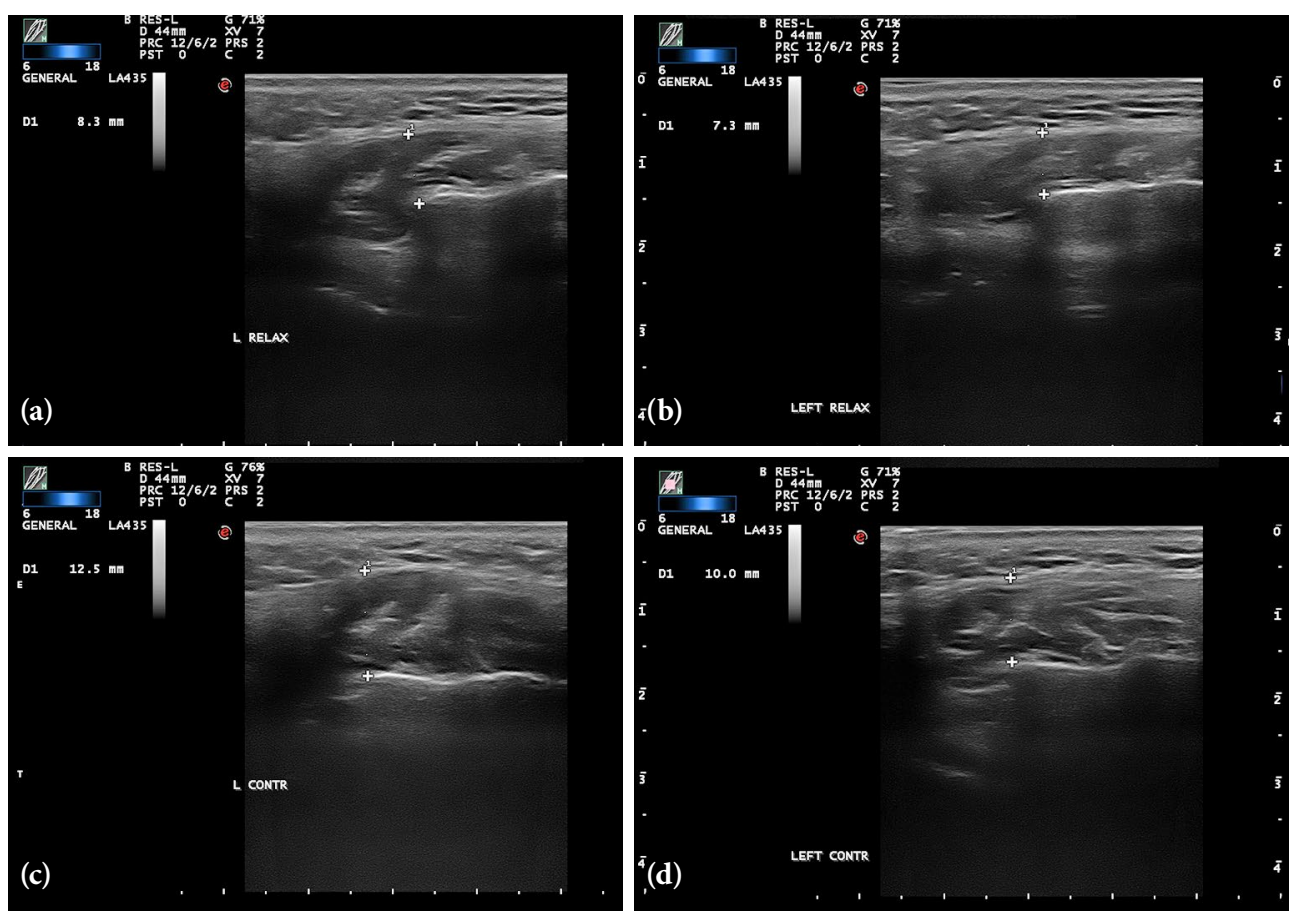

Figure 1. (a) Pre-treatment ultrasonographic image of relaxed masseter muscle. (b) Post-treatment ultrasonographic image of relaxed masseter muscle. (c) Pre-treatment ultrasonographic image of contracted masseter muscle. (d) Post-treatment ultrasonographic image of contracted masseter muscle. 
measured from the level of the ramus of the mandible, while the masseter muscle was relaxed and contracted (Figure 1). Average of the three measurements was gained for MT. After confirming the muscle with US, BoNT-A was injected. All US examinations were done by a single physician experienced for more than 10 years in musculoskeletal US. A post-injection US was performed to monitor complications such as hematoma.

\section{Botulinum toxin-A (BTX-A) injection}

The patients were treated using individualized BoNT-A injection dosages ( 30 to $50 \mathrm{U}$ ) and sites (one to two per muscle). A sterile, preservative-free, $0.9 \%$ sodium chloride was used to reconstitute $100-\mathrm{U}$ vials of freeze-dried BoNT-A (Botox ${ }^{\oplus}$; Allergan, Global Pharmaceuticals, Dublin, Ireland) according to manufacturer guidelines. A total of $100-\mathrm{U}$ vials were diluted with $2.0 \mathrm{~mL}$ of sodium chloride, resulting in a dose of $5 \mathrm{U}$ per $0.1 \mathrm{~mL}$. An 18-gauge needle was used to administer the sodium chloride. Gentle swilling was applied to reconstitute the vacuum-dried BTX-A to avoid disrupting the large molecular size. The BTX-A was distributed into two 1.0-mL syringes. All injections were administered using a 23 -gauge, $32-\mathrm{mm}$ needle.

\section{Maximal bite force measurements}

All patients were informed about the procedure prior to the assessment. The MBF measurements were carried out in the incisor area by the use of Istanbul bite force recorder for each patient. The reliability of this device for MBF measurements has been demonstrated both in vitro and in vivo. ${ }^{[16]}$ After two or three trial repetitions, the patients were asked to bite the apparatus for $5 \mathrm{sec}$ with maximum force and this was repeated three times with 2-min intervals. The highest value obtained from these three measurements was used for the analysis.

\section{Statistical analysis}

The study power analysis and sample size calculation were performed using the $G^{*}$ Power version 3.1.9.2 software (Heinrich-Heine-Universität, Düsseldorf, Düsseldorf, Germany). Accordingly, the study power was calculated as $80 \%$ with an effect size of 1.17 and alpha value of 0.05 . The sample size was calculated as 26 with a post-hoc power of the study of 1.0 .

Statistical analysis was performed using the IBM SPSS for Windows version 22.0 software (IBM Corp., Armonk, NY, USA). Descriptive data were expressed in mean \pm standard deviation (SD), median (min-max) or number and frequency. The distribution of the variables was checked using the Kolmogorov-Smirnov test. The Friedman analysis of variance was performed to compare the data from the parameters repeatedly measured and post-hoc analysis was applied for significant results. A $p$ value of $<0.05$ was considered statistically significant.

\section{RESULTS}

There were a total of 26 masseter muscles in 20 patients with masseter hypertrophy who underwent BoNT-A injection. Clinical and demographical features of the patients are summarized in Table 1 . Eight patients included in the study were using splints, and 17 patients had dental erosion.

There was a significant difference in US measurements of the relaxed and contracted masseter muscles between the baseline and post-treatment second week, first month, and third month values $(p<0.05)$. Additionally, in the US measurement of the relaxed masseter muscle, post-treatment third month values significantly differed from the second week values (Table 2, Figures 1 and 2).

The differences in the measurement of the line between the tragus and the angle of the mouth

\begin{tabular}{|c|c|c|}
\hline \multicolumn{3}{|c|}{$\begin{array}{c}\text { TABLE } 1 \\
\text { Clinical and demographical features of patients }(n=20)\end{array}$} \\
\hline Variables & $\mathrm{n}$ & Mean \pm SD \\
\hline Age (year) & & $28.1 \pm 6.9$ \\
\hline Unilateral & & $26.7 \pm 7.9$ \\
\hline Bilateral & & $29.6 \pm 5.4$ \\
\hline Sex $M / F$ & $3 / 17$ & \\
\hline Unilateral & $2 / 12$ & \\
\hline Bilateral & $1 / 5$ & \\
\hline Body mass index $\left(\mathrm{kg} / \mathrm{m}^{2}\right)$ & & $22.8 \pm 3.4$ \\
\hline Unilateral & & $21.8 \pm 3.7$ \\
\hline Bilateral & & $23.9 \pm 2.9$ \\
\hline MT USG relaxed (mm) & & $9.5 \pm 1.8$ \\
\hline Unilateral & & $9.5 \pm 1.7$ \\
\hline Bilateral & & $9.5 \pm 1.9$ \\
\hline MT USG contracted (mm) & & $13.9 \pm 2.4$ \\
\hline Unilateral & & $14.1 \pm 2.5$ \\
\hline Bilateral & & $13.7 \pm 2.4$ \\
\hline Tragus-angle line (mm) & & $11.2 \pm 0.7$ \\
\hline Unilateral & & $11.2 \pm 0.6$ \\
\hline Bilateral & & $11.0 \pm 0.8$ \\
\hline Maximal bite force $(\mathrm{N})$ & & $98.0 \pm 34.7$ \\
\hline Unilateral & & $99.3 \pm 37.1$ \\
\hline Bilateral & & $98.3 \pm 31.9$ \\
\hline
\end{tabular}



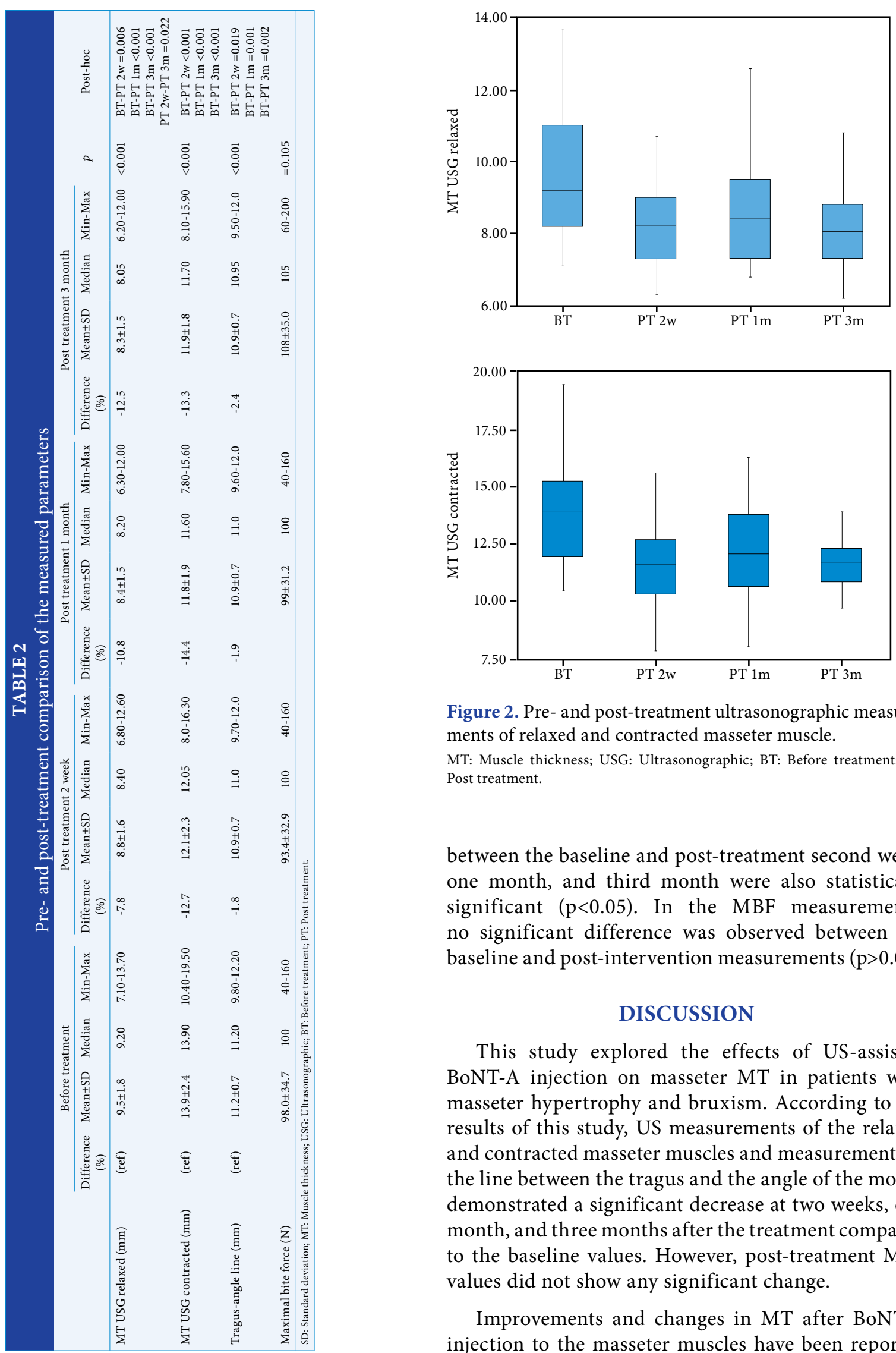

Figure 2. Pre- and post-treatment ultrasonographic measurements of relaxed and contracted masseter muscle.

MT: Muscle thickness; USG: Ultrasonographic; BT: Before treatment; PT: Post treatment.

between the baseline and post-treatment second week, one month, and third month were also statistically significant $(\mathrm{p}<0.05)$. In the $\mathrm{MBF}$ measurements, no significant difference was observed between the baseline and post-intervention measurements $(\mathrm{p}>0.05)$.

\section{DISCUSSION}

This study explored the effects of US-assisted BoNT-A injection on masseter MT in patients with masseter hypertrophy and bruxism. According to the results of this study, US measurements of the relaxed and contracted masseter muscles and measurements of the line between the tragus and the angle of the mouth demonstrated a significant decrease at two weeks, one month, and three months after the treatment compared to the baseline values. However, post-treatment MBF values did not show any significant change.

Improvements and changes in MT after BoNT-A injection to the masseter muscles have been reported 
in some studies. ${ }^{[10,11,16-18]}$ Most of the studies have used computed tomography (CT), which is expansive and contains high doses of ionizing radiation. ${ }^{[17,18]}$ Therefore, we used US to evaluate masseter muscle in our study. Musculoskeletal US is a useful imaging modality to quantify certain variables of the skeletal muscle such as MT, pennation angle, and fascicle length. In addition, the advantages of US are lack of ionizing radiation, being cheaper than $\mathrm{CT}$ and magnetic resonance imaging, ease of application, providing real-time imaging, guidance for the interventional procedures, high spatial resolution, serial evaluations, and widely availability. ${ }^{[19]}$

In the present study, US was used not only for evaluation of the MT, but also for the assistance to interventional procedures. In the literature, there are few studies using US guidance for the BoNT-A injection. Quezada-Gaon et al. ${ }^{[10]}$ used US for guidance to BoNT-A injection in 20 individuals. After the injection, most patients showed a symptomatic and cosmetic improvement. The authors concluded that US was a potent tool for guiding injection of BoNT-A into the masseter muscles and it helps to avoid potential complications. All injections in the current study were carried out with no complications under US guidance. Follow-up period was three months, consistent with the previous studies. ${ }^{[10,18]}$

When the post-treatment masseter MT's were evaluated by US, there was a $7.8 \%$ reduction at two weeks, $10.8 \%$ reduction at one month, and a $12.5 \%$ reduction at three months. Kim et al. ${ }^{[17]}$ and Yu et al. ${ }^{[20]}$ observed a $22 \%$ and $30 \%$ reduction in muscle volume, respectively by means of $\mathrm{CT}$, and our results are consistent with the study of Shome et al. ${ }^{[21]}$ who also used US measurements including 50 patients, showing an average of $8.4 \%$ and $12 \%$ reduction in $\mathrm{MT}$ at one and three months after the treatment, respectively.

Two studies previously reported a decrease in MBF after BoNT-A injection. Kim et al. ${ }^{[22]}$ measured a $20 \%$ decrease in mean MBF at two weeks after the injection in their series. Ahn and $\mathrm{Kim}^{[23]}$ also reported an approximately $40 \%$ decrease in the mean MBF at two weeks, compared to pre-treatment. Nevertheless, in both studies, this decline in MBF recovered gradually after four weeks to return to the pre-injection levels at 12 weeks. In contrast, no significant decrease was observed for the MBF in our study. Sipahi Calis et al. ${ }^{[2]}$ also reported that MBF did not change significantly after treatment in their patients. This fact could be attributed to the reference points and dosage of the BoNT-A injection and also to the method of MBF measurement. In addition, the line between the tragus and angle of the mouth decreased significantly in two weeks and thereafter, which improved the cosmetic perception in our patients, particularly those with unilateral involvement by reducing the asymmetry caused by muscle hypertrophy.

The present study has some limitations, including retrospective design and the lack of a control group receiving placebo injection. The lack of long-term follow-up and subjective evaluation of the patients' clinical status are the other limitations. Although our physician who performed US evaluation is an experienced specialist, the lack of intra-rater and interrater reliability can be deemed another limitation. Nonetheless, our results still appear to be clinically relevant.

In conclusion, MT decreases after a single dose of BoNT-A injection in patients with masseter muscle hypertrophy and US is a convenient imaging modality for BoNT-A injection to the masseter. Based on these findings, we strongly recommend clinicians to use US assistance in their clinical practice. Further prospective and long-term follow-up studies considering the repeat injections are warranted.

\section{Declaration of conflicting interests}

The authors declared no conflicts of interest with respect to the authorship and/or publication of this article.

Funding

The authors received no financial support for the research and/or authorship of this article.

\section{REFERENCES}

1. Yap AU, Chua AP. Sleep bruxism: Current knowledge and contemporary management. J Conserv Dent 2016;19:383-9.

2. Katsetos CD, Bianchi MA, Jaffery F, Koutzaki S, Zarella M, Slater R. Painful unilateral temporalis muscle enlargement: Reactive masticatory muscle hypertrophy. Head Neck Pathol 2014;8:187-93.

3. Shetty N, Malaviya RK, Gupta MK. Management of unilateral masseter hypertrophy and hypertrophic scar-a case report. Case Rep Dent 2012;2012:521427.

4. Arzul L, Corre P, Khonsari RH, Mercier JM, Piot B. Asymmetric hypertrophy of the masticatory muscles. Ann Chir Plast Esthet 2012;57:286-91.

5. Kebede B, Megersa S. Idiopathic masseter muscle hypertrophy. Ethiop J Health Sci 2011;21:209-12.

6. De la Torre Canales G, Câmara-Souza MB, do Amaral CF, Garcia RC, Manfredini D. Is there enough evidence to use botulinum toxin injections for bruxism management? A systematic literature review. Clin Oral Investig 2017;21:727-34. 
7. Awan KH. The therapeutic usage of botulinum toxin (Botox) in non-cosmetic head and neck conditions - An evidence based review. Saudi Pharm J 2017;25:18-24.

8. Al-Wayli H. Treatment of chronic pain associated with nocturnal bruxism with botulinum toxin. A prospective and randomized clinical study. J Clin Exp Dent 2017;9:e112-e117.

9. Tinastepe N, Küçük BB, Oral K. Botulinum toxin for the treatment of bruxism. Cranio 2015;33:291-8.

10. Quezada-Gaon N, Wortsman X, Peñaloza O, Carrasco JE. Comparison of clinical marking and ultrasound-guided injection of Botulinum type A toxin into the masseter muscles for treating bruxism and its cosmetic effects. J Cosmet Dermatol 2016;15:238-44.

11. To EW, Ahuja AT, Ho WS, King WW, Wong WK, Pang PC, et al. A prospective study of the effect of botulinum toxin A on masseteric muscle hypertrophy with ultrasonographic and electromyographic measurement. Br J Plast Surg 2001;54:197-200.

12. Pizolato RA, Gavião MB, Berretin-Felix G, Sampaio AC, Trindade Junior AS. Maximal bite force in young adults with temporomandibular disorders and bruxism. Braz Oral Res 2007;21:278-83.

13. Mäntyvaara J, Sjöholm T, Kirjavainen T, Waltimo A, Iivonen $\mathrm{M}$, Kemppainen $\mathrm{P}$, et al. Altered control of submaximal bite force during bruxism in humans. Eur J Appl Physiol Occup Physiol 1999;79:325-30.

14. Cosme DC, Baldisserotto SM, Canabarro Sde A, Shinkai RS. Bruxism and voluntary maximal bite force in young dentate adults. Int J Prosthodont 2005;18:328-32.

15. Diraçoğlu D, Alptekin K, Cifter ED, Güçlü B, Karan A, Aksoy C. Relationship between maximal bite force and tooth wear in bruxist and non-bruxist individuals. Arch Oral Biol 2011;56:1569-75.
16. Diraçoğlu D, Güçlü B, Alptekin K, Karan A, Aksoy C. Maximal bite force measurement by the "Istanbul bite force recorder". J PMR Sci 2008;11:117-23.

17. Kim HJ, Yum KW, Lee SS, Heo MS, Seo K. Effects of botulinum toxin type A on bilateral masseteric hypertrophy evaluated with computed tomographic measurement. Dermatol Surg 2003;29:484-9.

18. Kim JH, Shin JH, Kim ST, Kim CY. Effects of two different units of botulinum toxin type a evaluated by computed tomography and electromyographic measurements of human masseter muscle. Plast Reconstr Surg 2007;119:711-7.

19. Özçakar L, Kara M, Chang KV, Çarl AB, Akkaya N, Tok $F$, et al. Nineteen reasons why physiatrists should do musculoskeletal ultrasound: EURO-MUSCULUS/USPRM recommendations. Am J Phys Med Rehabil 2015;94:e45-9.

20. Yu CC, Chen PK, Chen YR. Botulinum toxin a for lower facial contouring: A prospective study. Aesthetic Plast Surg 2007;31:445-51.

21. Shome D, Khare S, Kapoor R. Efficacy of botulinum toxin in treating Asian Indian patients with masseter hypertrophy: A 4-year follow-up study. Plast Reconstr Surg 2019;144:390e-396e.

22. Kim KS, Byun YS, Kim YJ, Kim ST. Muscle weakness after repeated injection of botulinum toxin type A evaluated according to bite force measurement of human masseter muscle. Dermatol Surg 2009;35:1902-6.

23. Ahn KY, Kim ST. The change of maximum bite force after botulinum toxin type a injection for treating masseteric hypertrophy. Plast Reconstr Surg 2007;120:1662-6.

24. Sipahi Calis A, Colakoglu Z, Gunbay S. The use of botulinum toxin-a in the treatment of muscular temporomandibular joint disorders. J Stomatol Oral Maxillofac Surg 2019;120:322-5. 